\title{
The Drosophila orb RNA-binding protein is required for the formation of the egg chamber and establishment of polarity
}

\author{
Valerie Lantz, ${ }^{1}$ Jacqueline S. Chang, Jamila I. Horabin, Daniel Bopp, ${ }^{2}$ and Paul Schedl \\ Department of Molecular Biology, Moffett Laboratory, Princeton University, Princeton, New Jersey 08544 USA
}

\begin{abstract}
The orb gene of Drosophila encodes sex-specific germ-line proteins that contain two RRM-type RNA-binding domains. Here we report the distribution of Orb protein in wild-type, tumorous, and orb mutant ovaries. The wild-type distribution of Orb protein during oogenesis resembles that of its RNA, preferentially accumulating in the cytoplasm of the developing oocyte shortly after the formation of the 16-cell cyst. As anticipated from its germ-line expression, mutations in orb lead to female sterility. Analysis of the effect of orb mutants on the distribution of RNAs known to be required for oocyte differentiation and polarity suggests that orb functions in RNA localization at multiple points during oogenesis. In addition, phenotypic characterization of the orb mutants indicates that the gene is required early in oogenesis for formation of the 16-cell cyst. It then functions in the differentiation of the oocyte and is required for the three-dimensional reorganization of the germ cells in the cyst as well as for the establishment of normal germ-line-soma interactions in the egg chamber.
\end{abstract}

[Key Words: orb; RNA localization; anchoring; polarity; egg chamber; oogenesis]

Received October 13, 1993; revised version accepted January 13, 1994.

RNA localization has been implicated in many aspects of embryonic patterning. More than 20 years ago Kalthoff and co-workers found that UV irradiation or RNase treatment of the cytoplasm at the anterior end of early Smittia embryos disrupted the establishment of anterior-posterior polarity, producing animals with a double abdomen (bicaudal-like) phenotype (Kalthoff 1973, 1979; Kandler-Singer and Kalthoff 1976). Recent molecular and genetic experiments have provided direct evidence that localized maternal mRNAs play a key role in early development of several different organisms. In Xenopus oocytes, $V g 1$ RNA, which encodes a transforming growth factor- $\beta$ (TGF- $\beta$ )-like protein, is localized to the cortical region of the vegetal hemisphere (Melton 1987; Weeks and Melton 1987; Yisraeli and Melton 1988; Thomsen and Melton 1993) where it is thought to play a key role in inducing mesoderm. In Drosophila, the specification of anterior fate in the early embryo is dependent on proper localization of the maternal bicoid (bcd) mRNA during oogenesis (see St. Johnston and NüssleinVolhard 1992). bicoid mRNA is synthesized in the nurse cells and localized to the anterior cortex of the oocyte. It is translated after fertilization to generate a gradient of

Present addresses: ${ }^{1}$ Department of Biology, Washington University, St. Louis, Missouri 63130 USA; ${ }^{2}$ Zoologisches Institut der Universitat $\mathrm{Zu}$ rich, CH-8057 Zurich, Switzerland.
Bicoid protein, which then directs the expression of the zygotic genes that establish anterior pattern in the developing embryo (Driever and Nüsslein-Volhard 1988a,b).

RNA localization is required not only for the development of anterior structures in Drosophila, but also for many other aspects of embryonic patterning. The development of the posterior end of the Drosophila embryo depends on the proper localization of several mRNAs including oskar (osk) and nanos (nos). osk RNA accumulates at the posterior end of the oocyte late in oogenesis where osk functions in the organization of the germ plasm and the posterior localization of nos mRNA (Ephrussi et al. 1991). The Nos protein produced from this localized mRNA functions in the specification of abdominal segments (for review, see Lehmann 1992). Although dorsal-ventral polarity in the early embryo depends on the establishment of a nuclear gradient of Dorsal protein (Steward et al. 1988; for review, see Govind and Steward 1991), the initial selection of the dorsalventral axis of the egg, which occurs during oogenesis, appears to require the proper localization of at least two mRNAs, $f_{S}(1) K 10$ (K1O) and gurken (grk) (Haenlin et al. 1987; Cheung et al. 1992; Neuman-Silberberg and Schupbach 1993|. Genes involved in other aspects of oogenesis also appear to encode localized mRNAs. Transcripts from the Bicaudal-D (BiC-D) gene (Wharton and 
Struhl 1989; Suter and Steward 1991), which is required for the differentiation of the oocyte, and from hu-li tai shao (hts) (Yue and Spradling 1992), which is required for ring canal function, both localize to the presumptive oocyte at a very early stage in oogenesis.

While the importance of mRNA localization in a variety of developmental systems is now well documented, little is known about the underlying molecular mechanisms. The fact that only a few of the mRNA species in the Drosophila oocyte are localized suggests that there is a specialized machinery that transports these RNAs from their site of synthesis in the nurse cells to particular regions within the oocyte. Implicit in this idea are cis-acting signals, which first must mark the RNA for transport into the oocyte, and second anchor them to specific regions within the oocyte. Indeed, it has been shown that many of the localized transcripts have elements in their $3^{\prime}$ untranslated regions $\left(3^{\prime}\right.$ UTRs) that serve as signals for localization to the oocyte or to specific regions within the oocyte (for review, see MacDonald 1992). The localization machinery must also include the trans-acting factors that mediate the transport and anchoring of the RNAs with the appropriate signals. Such factors would include general components of the cytoskeleton such as microtubules (Pokrywka and Stephenson 1991; Theurkauf et al. 1992). In addition, genetic studies have identifed severals genes that are required for the proper localization of specific RNAs and hence might encode such trans-acting factors. The transport of $b c d$ mRNA into the oocyte and its anchoring to the anterior cortex is dependent on the activity of at least three maternal genes, exuperantia (exu), swallow $(s w w)$, and staufen (stau) (Frohnhöfer and Nüsslein-Volhard 1987; St Johnson et al. 1989; MacDonald et al. 1991; Marcey et al. 1991; Pokrywka and Stephenson 1991). Staufen protein, together with the gene products of cappucino (capu) and spire (spir), are required for the localization of osk RNA (Lehmann 1992).

Another gene that might encode a component of the mRNA localization machinery of the egg is oo18 RNAbinding (orb). or $b$ is expressed only in the germ line and is predicted to encode female- and male-specific proteins that contain two RRM-type RNA-binding domains. Moreover, like many of the maternal mRNAs involved in establishing polarity in the egg and embryo, orb mRNA shows a complex pattern of localization during oogenesis (Lantz et al. 1992). In this paper we have used antibodies directed against Orb protein to analyze its distribution in wild-type ovaries and in mutants that block oogenesis at different stages. We have also identified several orb mutants and characterized their phenotype in some detail.

\section{Results}

\section{Antibodies to Orb protein}

To learn more about the possible role of the orb gene in oogenesis and spermatogenesis monoclonal antibodies were generated against an Orb fusion protein expressed in bacteria (see Materials and methods). Shown in Figure 1A is a Western blot of proteins from ovaries and testes probed with antibodies directed against this fusion protein. In ovaries two proteins that migrate between the 100.6- and 97.4-kD molecular mass standards are detected. The presence of this doublet could be explained by the fact that the ovarian orb mRNA has two closely spaced AUGs that could function as initiation codons. If the first AUG is used, the predicted Orb protein would be $98.8 \mathrm{kD}$. If the second is used /and it is in a context that more closely matches consensus for Drosophila translation initiation signals), the predicted protein would be $97 \mathrm{kD}$. Because both protein species appear to migrate more slowly than predicted, the doublet could also be the result of post-translational modification. This possibility seems more likely as Christerson and $\mathrm{McK}$ earin (this issue) have found that both Orb protein species are expressed in an orb mutant in which the first

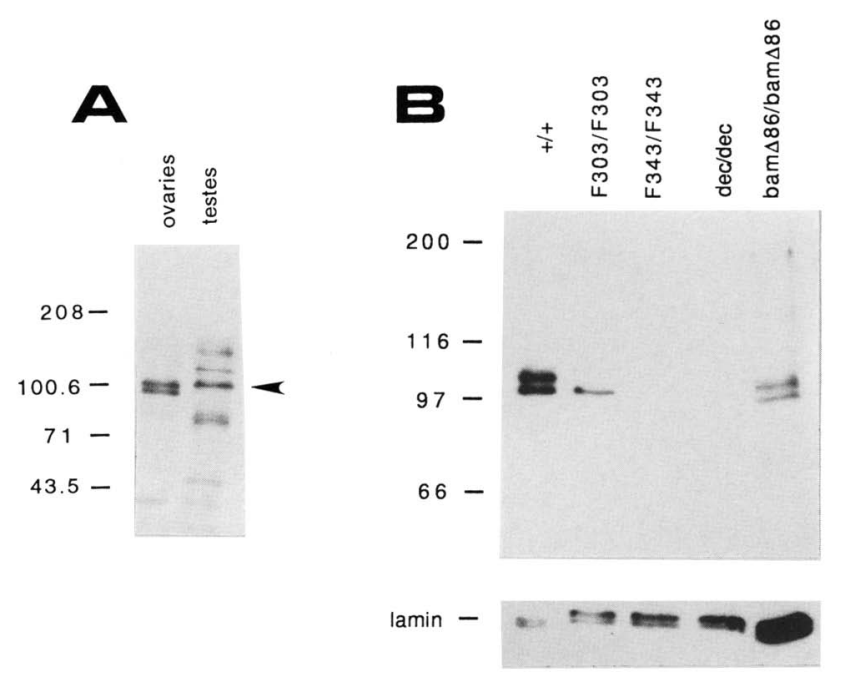

Figure 1. (A) Orb protein in ovaries and testes. A Western blot of Ore- $R$ ovaries (1/4 ovary) and testes (15 testes) probed with Orb monoclonal antibodies. Wild-type ovaries express two isoforms of the Orb protein in the range of $97-100 \mathrm{kD}$. In testes a major band of $\approx 99 \mathrm{kD}$ is detected. This protein comigrates with the slower migrating ovarian species. In addition, there are several higher and lower molecular weight bands. One of the higher molecular weight species appears in blots with the secondary antibody alone. The other bands are not always seen and their yield is quite variable. At least some of the lower molecular weight bands are likely to be breakdown products of Orb. Other bands may be cross-reacting protein species. $(B)$ Orb protein in orb and bam mutant ovaries. A Western blot of orb and bam mutant ovary extracts probed with Orb antibodies. As a control for the amount of protein loaded, the blot was stripped and reprobed with a polyclonal antibody that detects nuclear lamin (Gruenbaum et al. 1988) $(+1+$ ) Orb protein from wild-type ovaries. Orb protein is not detected in orb $b^{F 343}$ and orb ${ }^{\text {dec }}$ mutant ovaries, whereas only the lower isoform of Orb protein is detected in $o r b^{F 303}$ mutant ovaries. Low levels of both Orb isoforms are detected in the $b_{a m^{\Delta 86}}$ mutant ovaries (compare relative levels of nuclear lamin). 
AUG is deleted. In testes, conceptual translation of the $3.2-\mathrm{kb}$ orb message predicts a $97.6-\mathrm{kD}$ protein. A protein of the expected size is observed in testes. In addition, other bands (which presumably correspond to breakdown products or cross-reacting protein species) are sometimes detected (see Fig.1A).

\section{Distribution of Orb protein during oogenesis}

To determine whether Orb protein, like orb RNA, is localized during oogenesis, we stained wild-type ovaries with the Orb antibody. As can be seen in Figure 2, expression of the protein is apparently restricted to the germ line and no staining above background is evident in the srmatic follicle cells. Moreover, as was the case for orb RNA (Lantz et al. 1992), Orb protein displays a complex pattern of accumulation during oogenesis. In region 1 of the germarium (Mahowald and Kambysellis 1980), at most only very low levels of Orb protein appear to be present in the stem cells, the cystoblasts and the twoand four-cell cysts (Fig. 2A,C). This is consistent with previous studies on the expression of orb RNA, which indicated that there is very little message in this part of the germarium. Significant levels of Orb protein first begin to accumulate between the 8- and 16-cell stage, and by the time the 16-cell cysts are formed in region 2 of the germarium, high levels of Orb protein are evident. The protein is exclusively cytoplasmic at this stage and at sub-
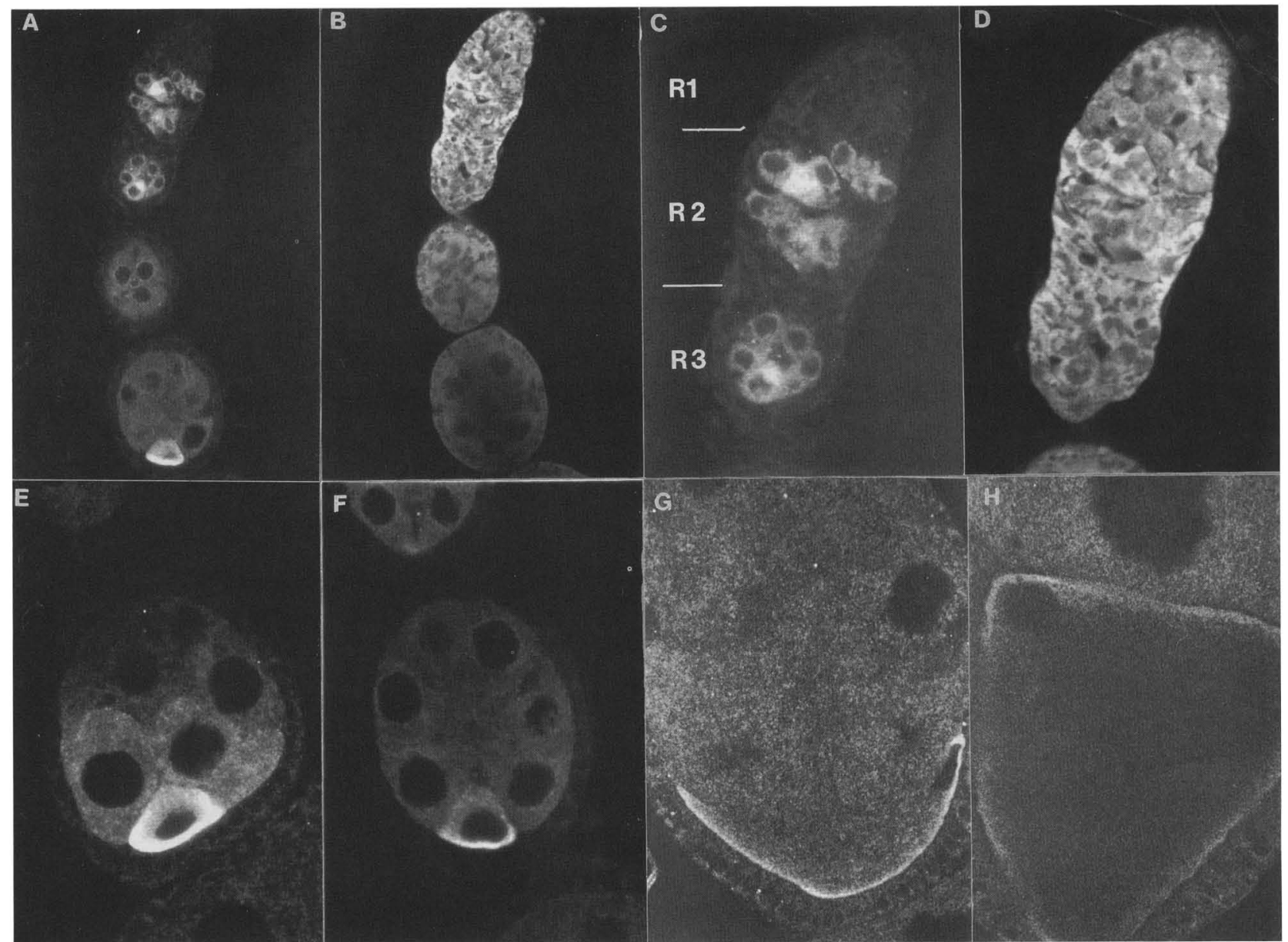

Figure 2. Confocal images showing the distribution of Orb protein during oogenesis. Orb protein in wild-type ovaries is seen as a cytoplasmic protein that is expressed only in the germ-line cells $(A, C, E-H)$. The RNA/DNA distribution (propidium iodide staining) is shown in $B$ and $D .(A, B)$ Germarium and stages $1-7 \mathrm{egg}$ chambers. Orb protein preferentially accumulates in the presumptive oocyte and is localized cortically in the posterior of the oocyte at stage $7 .(C, D)$ The distal tip of the ovariole showing the germarium. Regions 1-3 of the germarium are indicated. The Orb protein is first detected at high levels in region 2 of the germarium. It preferentially accumulates in the presumptive oocytes of region 2 cysts. $|E|$ A stage- 5 egg chamber. A gradient of Orb protein within the chamber is clearly visible; the nurse cells farthest from the oocyte have the lowest levels of protein. Greater levels of Orb protein are detected in the nurse cells closest to the oocyte, and peak levels of protein are in the oocyte. Note that the posterior end of the oocyte has the most protein. This can be seen clearly in the stage-7 egg chamber $(F) .(G)$ Stage-9 egg chamber. Orb protein accumulates along the cortex of the oocyte. $(H)$ Stage-10 egg chamber. Orb protein accumulates along the cortex of the oocyte with slightly higher levels at the anterior end of the oocyte, above the nucleus. In $A-H$; the anterior end of the chambers is at the top. 
sequent stages of oogenesis. Initially, Orb protein is present in all the cells of the newly formed 16-cell cysts; however, the protein distribution is not uniform, and it appears to be more concentrated in a subset of the cells in the cyst. As the cysts develop, Orb protein, like the RNA (Lantz et al. 1992), begins to preferentially accumulate in only one of the cells in the cyst, the presumptive oocyte (Fig. 2C).

The accumulation of Orb protein in the oocyte becomes more pronounced as oogenesis progresses (Fig. 2A). By stage 7 Orb protein preferentially concentrates along the cortex at the posterior edge of the oocyte while there is much less protein on the anterior side of the oocyte (Fig. 2F). orb RNA is also localized at the posterior edge of the oocyte during these stages of oogenesis. At the onset of vitellogenesis, stage 8 , the orb message capping the posterior end of the oocyte disappears, and instead the RNA accumulates at the anterior end of the oocyte along the nurse cell-oocyte border. This accumulation persists through stage 10 (Lantz et al. 1992). A somewhat different result is obtained for Orb protein. As shown for the stage 9 chamber in Figure 2G, Orb protein appears to be distributed along the entire cortex of the oocyte including the posterior pole. High levels of Orb protein can also be detected in the oocyte along the nurse cell-oocyte border. This is evident in the stage 10 chamber shown in Figure $2 \mathrm{H}$. Another difference between the orb RNA and protein distribution is the fact that significant levels of protein are generally present in nurse cells, whereas only very low levels of RNA are detected.
Moreover, as illustrated in Figure 2E, there is a graded distribution of protein in nurse cells such that the highest levels are found in the nurse cells closest to the oocyte, whereas progressively lower levels are present in the nurse cells further away from the oocyte. This gradient would suggest that at least some portion of the Orb protein is synthesized in nurse cells and subsequently transported to the oocyte.

\section{Localization of Orb protein is perturbed in Bic-D and egalitarian mutant ovaries}

Hypomorphic mutations in egalitarian (egl) and Bic-D block oogenesis at an early stage. Flies homozygous for mutations in either of these genes have ovaries that give rise to 16-cell cysts that become surrounded by somatically derived follicle cells; however, the oocyte fails to differentiate properly and all 16 cells develop as nurse cells. Because both these genes are required for the proper localization of orb RNA to the presumptive oocyte in early egg chambers (Lantz et al. 1992), it was of interest to determine whether they are also required for the localization of Orb protein. Figure $3(\mathrm{D}, \mathrm{E})$ shows that the distribution of Orb protein in the cysts and egg chambers formed in the egl mutants egl $1^{\text {WUSO }}$ and $e g 1^{R C 12}$ is abnormal. As in wild type, Orb protein begins concentrating in a subset of the cells in the early region $2 \mathrm{egl}$ cysts. However, unlike wild type, relatively high levels are also present in most of the other cells in these early cysts, and by the time cysts reach region 3 of the germa-
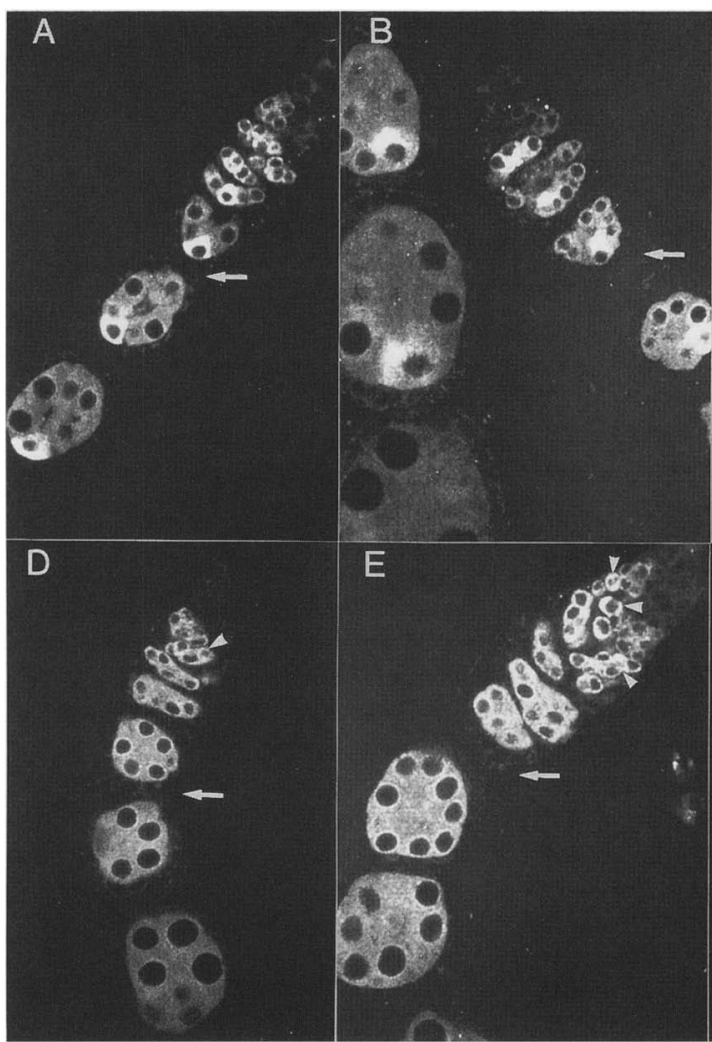

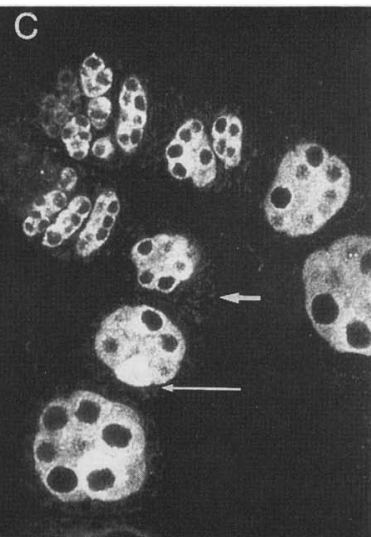

F
Figure 3. Confocal images showing the distribution of Orb protein in Bic-D and eg1 mutant ovaries. $(A)$ Wild-type ovaries. $(B)$ $B i c-D^{R 26}$ mutant ovaries. Orb protein is localized to the presumptive oocyte as in wild-type ovaries. Unlike wild-type, the localization appears to be mostly at the anterior rather than posterior end of the oocyte. (C) Bic-D $D^{P A 66}$ mutant ovaries. Early germarial stages show accumulation of protein in a few cells of the cyst. However, the level in the other cells is higher than that seen in wild-type cysts. This is clearly evident in the older chambers where Orb protein is localized to the presumptive oocyte /long arrow) but high levels of protein persist in the rest of the cells in the chamber. $(D)$ egl ${ }^{\text {wU5O }}$ mutant ovaries. $(E)$ egl ${ }^{R C 12}$ mutant ovaries. Early cysts in egl ovaries show weak protein accumulation in some cells but Orb protein becomes uniformly distributed as the cysts develop. $\{F\}$ Negative control of wild-type ovaries. Short arrows indicate the end of the germarium. Arrowheads indicate weak Orb protein accumulation. Anterior is at the top. 
rium, Orb is uniformly distributed throughout the mutant chambers instead of being concentrated in the presumptive oocyte.

A somewhat different result was obtained for the Bic-D mutants, Bic- $D^{R 26}$ and Bic- $D^{P A 66}$. In $B i c-D^{R 26}$ ovaries, Orb protein is first distributed in a graded fashion in the newly formed cysts, and as the cysts mature it begins to concentrate in the cells located at the posterior end of the cyst (Fig. 3B). Unlike wild type, high levels of protein are often present in several of these posterior cells instead of being concentrated only in the presumptive oocyte. In older R26 egg chambers there is a marked reduction in the level of Orb protein in the nurse cells much like wild type; however, the distribution of Orb protein in the presumptive oocyte (posterior-most cell of the chamber) appears irregular and diffuse, and often the highest levels of protein are toward the anterior (rather than the posterior) of the oocyte. The localization of Orb protein is disrupted more severely in Bic- $D^{P A 66}$ (Fig. 3C). Although Orb protein appears to concentrate in the presumptive oocyte as the Bic- $D^{P A 66}$ cysts mature, quite high levels of protein persist in the other cells of the chambers. This distribution is similar but perhaps not identical to the distribution pattern of orb RNA in Bic$D^{P A 66}$; in early mutant chambers the RNA is marginally concentrated in one or a few cells, whereas in later chambers localized RNA disappears altogether (Lantz et al. 1992).

\section{Identification of orb mutants}

The orb gene appears to be expressed only in the germ line, and mutations that disrupt orb function might be expected to result in female (and/or male) sterility. In situ hybridization experiments map the orb gene to 94E11-13, a region of the third chromsome uncovered by $D f(3 R) M S u 244$ (Reuter et al. 1986; Wustmann et al. 1989), which deletes the interval 94D-95A3. We used this deficiency to screen a collection of third chromosome female steriles (from C. Nüsslein-Volhard, Max Planck Institut für Entwicklungsbiologie, Tübingen, Germany) for potential mutations in the orb gene. We identified two female sterile mutants, $F 303$ and $F 343$, that were uncovered by the deficiency and also failed to complement each other. Neither showed any obvious rearrangments in the orb gene in genomic Southern blots. However, we found that they were allelic to a P-element-induced female sterile mutation, dec, isolated by Christerson and McKearin (this issue). Genomic Southern analysis of $d e c$ indicates that it contains a P-element insertion in one of the exons encoding the 5 '-leader sequence of the female orb mRNA /at +500 position in the orb D5 cDNA of Lantz et al. 1992; Christerson and McKearin, this issue). Hence, all three mutations (as well as a revertant of orb $b^{d e c}$, orb $b^{m e l}$, described in Christerson and McKearin, this issue) are likely to disrupt orb gene function.

As a preliminary phenotypic characterization, ovaries were dissected from three of the orb mutants, F343, dec, and F303, and stained with Hoechst (33258; data not shown) (or Yo Pro see Fig. 7, below) to detect nuclear DNA. On the basis of this analysis, the three mutants can be placed into two phenotypic classes (Table 1). The most severe effects are displayed by the class I alleles, $o r b^{d e c}$ and $o r b^{F 343}$. In both mutants the ovaries are very small and have a morphology suggesting that oogenesis is blocked at some step in cyst development, which normally occurs in late region 1 or early region 2 of the germarium. Egg chambers surrounded by somatically derived follicle cells are rarely formed in either mutant and we observe few if any polyploid (nurse cell-like) nuclei. Instead, the ovary consists of germarium-like structures populated by many small undifferentiated cells much like those found in some of the tumorous ovary mutants. Ovarian development is also arrested at a relatively early stage in the moderate class II allele, or $b^{F 303}$. However, in contrast to the more severe class I alleles, at least some aspects of germarial development proceed normally in or $b^{F 303}$, and we typically observe a few egg chambers (about three to five) that have pinched off from the germarium. Although these chambers contain several germline cells with polyploid nuclei (indicating that nurse cells have begun to differentiate), the overall morphology of these chambers is aberrant. Frequently, the somatic follicle cells do not completely surround the germ-line cyst, and germ cells often exclude the somatic follicle cells from their normal location in the egg chambers (see Fig. 4B,C) (The or $b^{\text {dec }}$ revertant orb $b^{\text {mel }}$ is a weak class III allele: see Christerson and McKearin, this issue).

\section{Orb protein expression in the orb mutants}

Analysis of Orb protein in the class I and II alleles is consistent with this phenotypic classification. Figure 1B shows a Western blot of ovarian extracts prepared from the orb mutants and, as a control, from a bag of marbles (bam) mutant. bam is thought to play a role in the control of cystoblast and/or very early cystocyte (two- and four-cell cysts/ divisions and bam mutants have abnormal germaria containing many undifferentiated and dis-

Table 1. Phenotype of orb mutant ovaries

\begin{tabular}{|c|c|c|}
\hline Class & Allele & Phenotype \\
\hline I (most severe) & $\begin{array}{l}\operatorname{dec}^{a} \\
{\text { F } 343^{b}}^{b}\end{array}$ & $\begin{array}{l}\text { egg chambers are not pinched } \\
\text { off; older cysts degenerate }\end{array}$ \\
\hline $\begin{array}{c}\text { II (less severe } \\
\text { than I) }\end{array}$ & $\mathrm{F} 33^{\mathrm{b}}$ & $\begin{array}{l}\text { pseudo-egg chambers form } \\
\text { containing pseudo-nurse } \\
\text { cells; follicle cells do not } \\
\text { completely surround egg } \\
\text { chamber }\end{array}$ \\
\hline III (weakest) & $\mathrm{mel}^{\mathrm{a}}$ & $\begin{array}{l}\text { maternal effect embryonic } \\
\text { lethal; ventralization/ } \\
\text { dorsalization of chorion; } \\
\text { posterior abdomen defects; } \\
\text { pole cells fail to form }\end{array}$ \\
\hline
\end{tabular}

\footnotetext{
${ }^{a}$ Alleles were isolated by D. McKearin and L. Christerson (this issue).

${ }^{b}$ Alleles were isolated by Nüsslein-Volhard laboratory.
} 


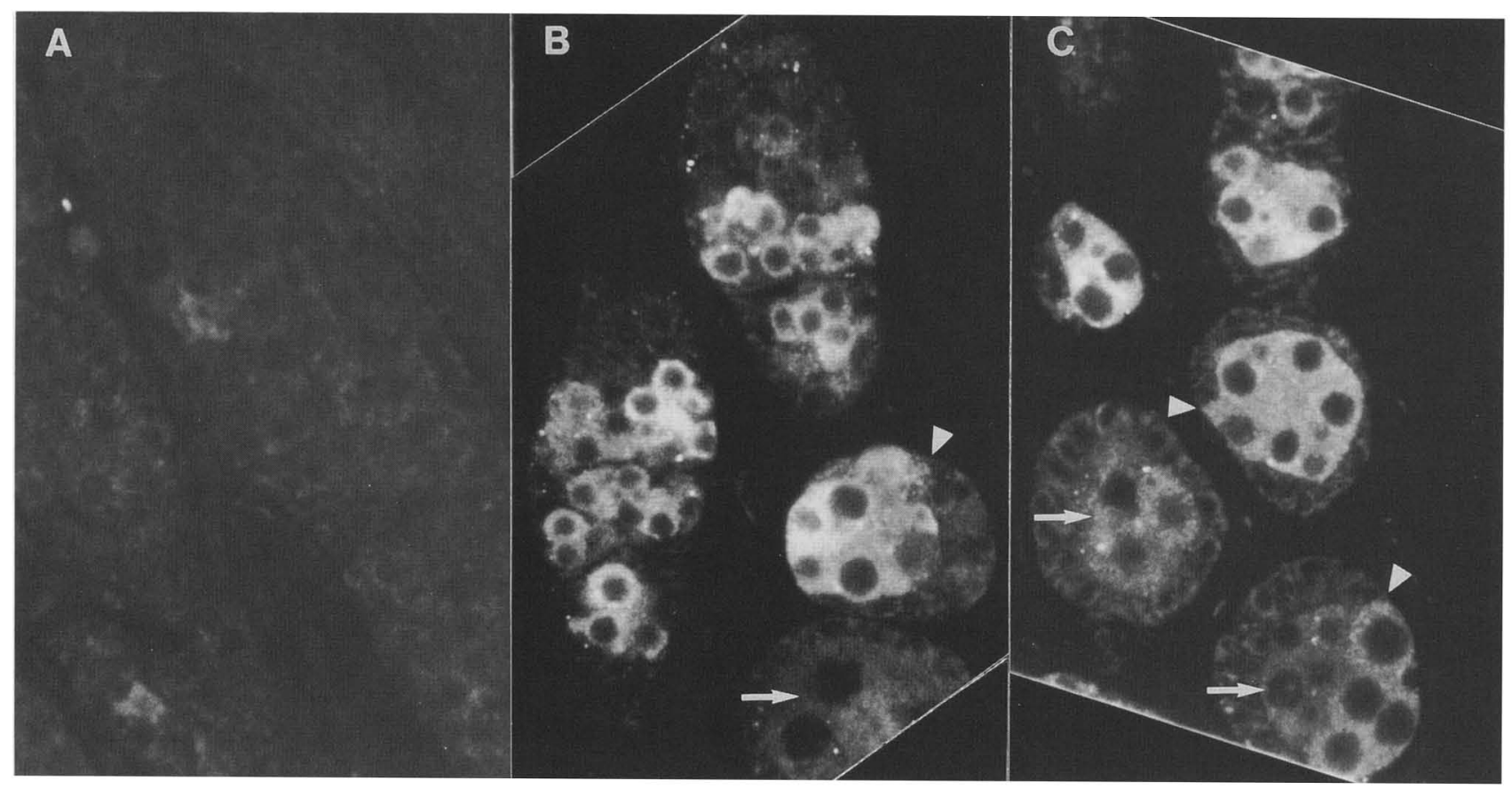

Figure 4. Distribution of Orb protein in $o r b^{F 343}$ and orb $b^{F 303}$ mutant ovaries. Confocal images of orb $b^{F 343}$ ovarioles $(A)$ and orb $b^{F 303}$ ovarioles $(B, C)$. No protein is detected in or $b^{F 343}$ ovarioles. The image has been overexposed so that the tissue can be weakly detected. The distribution of Orb protein in $\operatorname{orb}^{F 303}(B, C)$ mutant ovaries shows poor accumulation in a subset of the cells. Note that the later chambers have low levels of protein (arrows). Also, the follicle cells of chambers that have pinched off from the germarium appear to be displaced by the germ cells and do not completely surround the cyst (arrowheads).

organized cells (McKearin and Spradling 1990). Although mutations in bam block oogenesis very early in cyst development, both forms of the Orb protein can be detected in extracts from bam mutant ovaries. As can be seen in Figure 1B, only the smaller of the two isoforms (the $98-\mathrm{kD}$ species) is present in the class II orb mutant allele, F303. The fact that bam ovaries express both isoforms would suggest that the defect in Orb protein expression in $F 303$ is not an indirect consequence of the arrested ovarian development, but rather may correspond to the F303 lesion. In addition to lacking one isoform, the Orb protein produced in F303 mutants is not properly localized (Fig 4B,C). In wild-type ovaries, Orb protein begins to concentrate into a single cell, the presumptive oocyte, as the 16-cell cysts progress through region 2 of the germarium. In F303 Orb protein also appears to accumulate in a single cell (or group of cells) as the mutant cysts progress through the germarium; however, unlike wild type, relatively high levels of protein persist in most of the other cells in the cyst. In addition, the cell (or cells) that has the highest level of protein is usually not located at the posterior end of the cyst, but instead is near the center of the cyst, or off towards one of the sides. Soon after the mutant chambers pinch off from the germarium, there is a substantial reduction in the level of Orb protein (see arrow in Fig. 4B,C).

The class I alleles, orb $b^{d e c}$ and $o r b^{F 343}$, have a more severe effect on Orb protein expression than $\mathrm{Orb}^{\mathrm{F} 303}$. In these two mutants, neither of the Orb protein isoforms can be detected (Fig. 1B; see Fig. 4A) even when the gels were overloaded for protein extracts or when probed with monoclonal antibodies directed against different epitopes of Orb. These findings suggest that $o r b^{d e c}$ and $o r b^{F 343}$ may be protein nulls. Consistent with this suggestion, little or no orb message is detected in either orb $b^{\text {dec }}$ or $o r b^{F 343}$ ovaries (data not shown). In the case of $o r b^{d e c}$, the reduction in the level of message is likely to be attributable to the transposon insertion at the $5^{\prime}$ end of the female mRNA /Christerson and McKearin, this issue). Genomic Southern analysis revealed no obvious lesions in $o r b^{F 343}$, and it is unclear at present why we do not detect orb mRNA in this mutant.

Though a male-specific form of orb is expressed in testes, none of the mutants result in male sterility. Because the $5^{\prime}$ exons of the male and female Orb protein are different (Lantz et al. 1992), it is possible that these mutations do not affect the protein expressed in males. This seems to be the case for or $b^{d e c}$. The transposon in orb dec disrupts one of the female-specific exons but is upstream of all of the known male-specific exons (Christerson and McKearin, this issue). Western blots of testes from orb $b^{\text {dec }}$ males indicate that the same forms of Orb protein observed in wild-type testes are expressed by this mutant (data not shown). This is also true for or $b^{F 303}$. However, a quite different result is obtained for or $b^{F 343}$. We do not detect the predicted $99-\mathrm{kD}$ male Orb protein in testes from this mutant (data not shown). Because the female Orb protein is also missing in orb $b^{F 343}$, this result would 
suggest that the $F 343$ lesion disrupts a region of the gene that is required for the production of the major forms of both the male and female Orb proteins. Because the $F 343$ mutation is female sterile, but male fertile, these findings raise the possibility that the male Orb protein is not essential for spermatogenesis.

\section{Progression through oogenesis of the orb mutants}

To further characterize the ovarian phenotype of the different orb alleles, we examined mutant ovaries for the expression of several markers for oogenic development.

Distribution of bam RNA in orb mutant ovaries The bam gene provides a good marker for the very early stages of female germ-line development (McKearin and Spradling 1990). The RNA accumulates at very high levels in the cystoblasts and two-cell cysts and then rapidly turns over, probably prior to the formation of the fourcell cysts (see Fig. 5A,D; D. McKearin, pers. comm.). If the germ cells in orb mutant ovaries have developed beyond this very early stage, they might be expected to regulate bam expression normally and show the wildtype expression pattern of bam RNA. In contrast, if development of the germ cells in the orb mutant ovaries is arrested prior to when bam is normally turned off, the germ cells might show persistent bam expression. The pattern of bam expression in the three orb mutants is shown in Figure 5(C-E). As a control, we also examined the expression of bam RNA in a female sterile allele of
Figure 5. Expression of bam RNA in orb mutant ovaries. Whole-mount preparations of ovaries were probed with a digoxigeninlabeled bam. The end of the germarium in wild-type, or $b^{F 303}$ and $S x l^{f 4}$ ovaries is indicated by an arrowhead. (A) Wild-type ovary. (B) bam $^{\Delta 86}$ ovary (stained for the same amount of time as $o r b^{\text {dec }}$ ovaries as a negative control). (C) orb $b^{F 303}$ ovary. $(D)$ orb $b^{F 343}$ ovary. $(E)$ orb ${ }^{\text {dec }}$ ovary. $(F) S x l^{f 4}$ ovary. Germarium and early egg chambers are shown in each case. In wild-type ovaries bam RNA is restricted to region 1 of the germarium. $o r b^{F 303}$, or $b^{F 343}$, and orb $b^{d e c}$ ovaries show the shutdown of bam expression as seen in wild-type ovaries. In contrast, the germaria of $S_{X} I^{f 4}$ ovaries the accumulation of bam RNA does not appear to shut down, and cells throughout much of the germarium continue to accumulate bam RNA. bam RNA is also detected in the tumorous cysts that become surrounded by follicle cells and pinched off from the germarium. In older tumorous cysts it disappears.

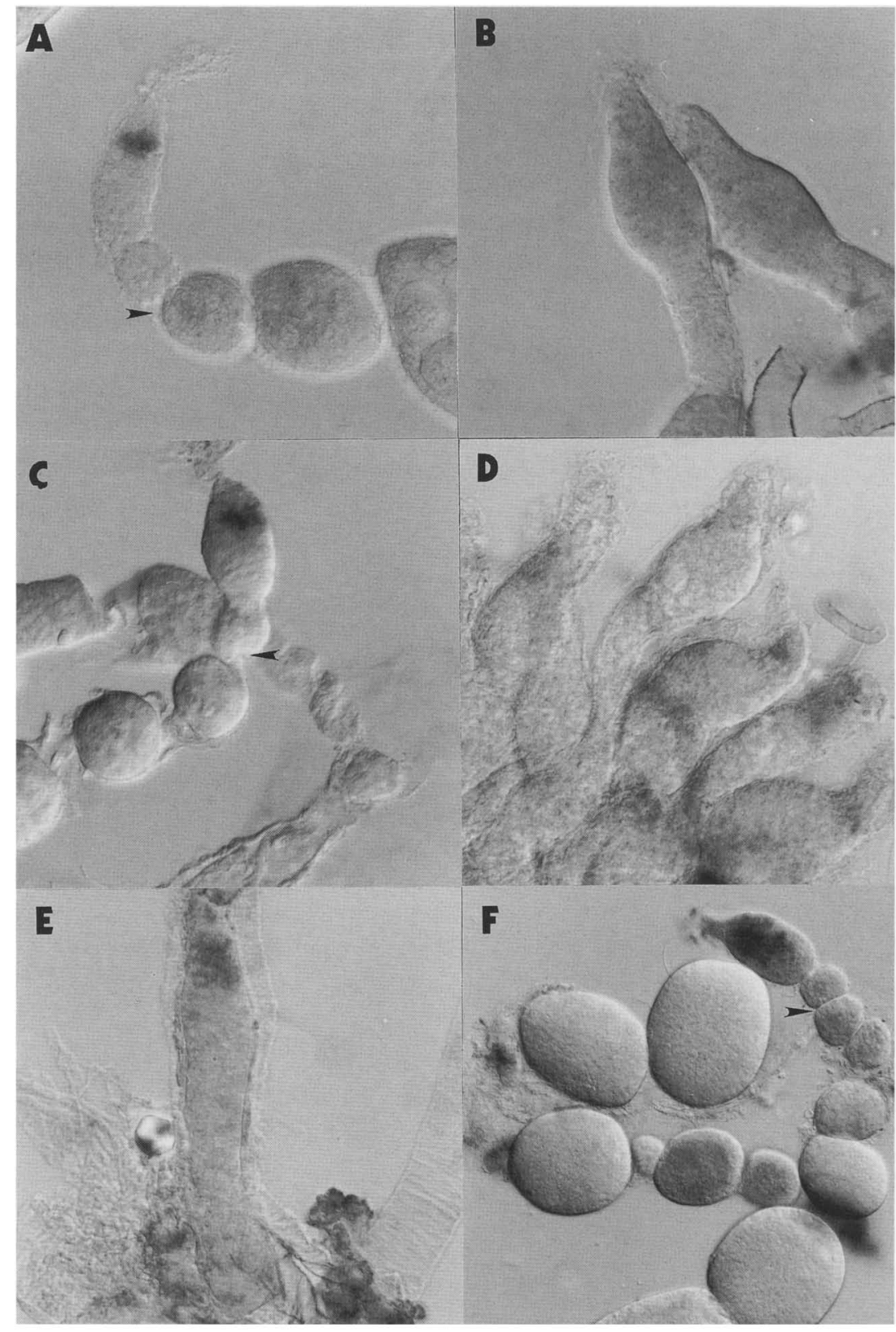


Sex-lethal, $S x l^{f 4}$, which also has a tumorous ovary phenotype.

In the $\mathrm{SxI}^{f 4}$ mutant bam expression is abnormal (Fig. $5 F$ ). bam transcripts are present at high levels throughout the germarium and can even be detected in some of the younger cysts that have budded off from the germarium. A different result is obtained for the orb mutants. Although the level of bam RNA may be slightly reduced in $o r b^{d e c}$ and $o r b^{F 343}$, the pattern of expression in all three mutants resembles that observed in wild type-it is essentially restricted to the cystoblasts and very early cysts in region 1 of the germarium. A simple interpretation of these findings is that in all three or $b$ mutants, the germ cells progress beyond the stage when bam expression is normally turned off.

Distribution of Sex-lethal protein in orb mutant ovaries Early cyst development in wild-type ovaries is accompanied by a dramatic change in the subcellular distribution of Sxl protein (Bopp et al. 1993). Very high levels of Sxl protein are observed in the stem cells, cystoblasts, and two-cell cysts (Fig. 6A). Moreover, in contrast to the soma, where Sxl protein is nuclear, the Sxl protein in these early germ cells is predominantly cytoplasmic. In the posterior half of region 1 of the germarium, which contains the four- and eight-cell cysts, there is an abrupt transition in the level and distribution of Sxl protein. As illustrated for wild-type ovaries in Figure $6 \mathrm{~A}$, most if not all of the cytoplasmic protein disap- pears, and only a very low level of nuclear protein remains. This transition does not, however, occur in bam mutant ovaries, which appear to arrest development between the two- and four-cell cyst (see Fig. 6D). In contrast, in the orb mutants, dec, F343, and F303, the pattern of Sxl protein accumulation in germ cells in region 1 of the germarium resembles that observed in wild-type ovaries. This is shown for F343 and F303 in Figure 6(B,C). These results would argue that oogenesis in the orb mutants is blocked at a point after the four- or eight-cell cysts have formed.

Ring canals in orb mutant ovaries Another marker for assessing oogenic development are the ring canals that interconnect the germ cells in each cyst. The cystoblast undergoes four mitotic divisions with incomplete cytokinesis to give rise to the 16-cell cyst (King 1970). Each cell in the cyst remains connected to the other cells by one or more ring canals that form at the sites of incomplete cell division. Two of the cells in the 16-cell cyst (the oocyte and one nurse cell) have four ring canals, whereas the remaining cells have three-, two-, or one-ring canals depending on their position in the cystoblast lineage. The ring canals as well as the actin filament network inside each cell can be observed with rhodamine-labeled phalloidin, which binds to polymerized actin. Confocal images of wild-type and orb mutant ovaries stained with rhodamine-labeled phalloidin and counterstained with the nucleic acid dye Yo Pro are

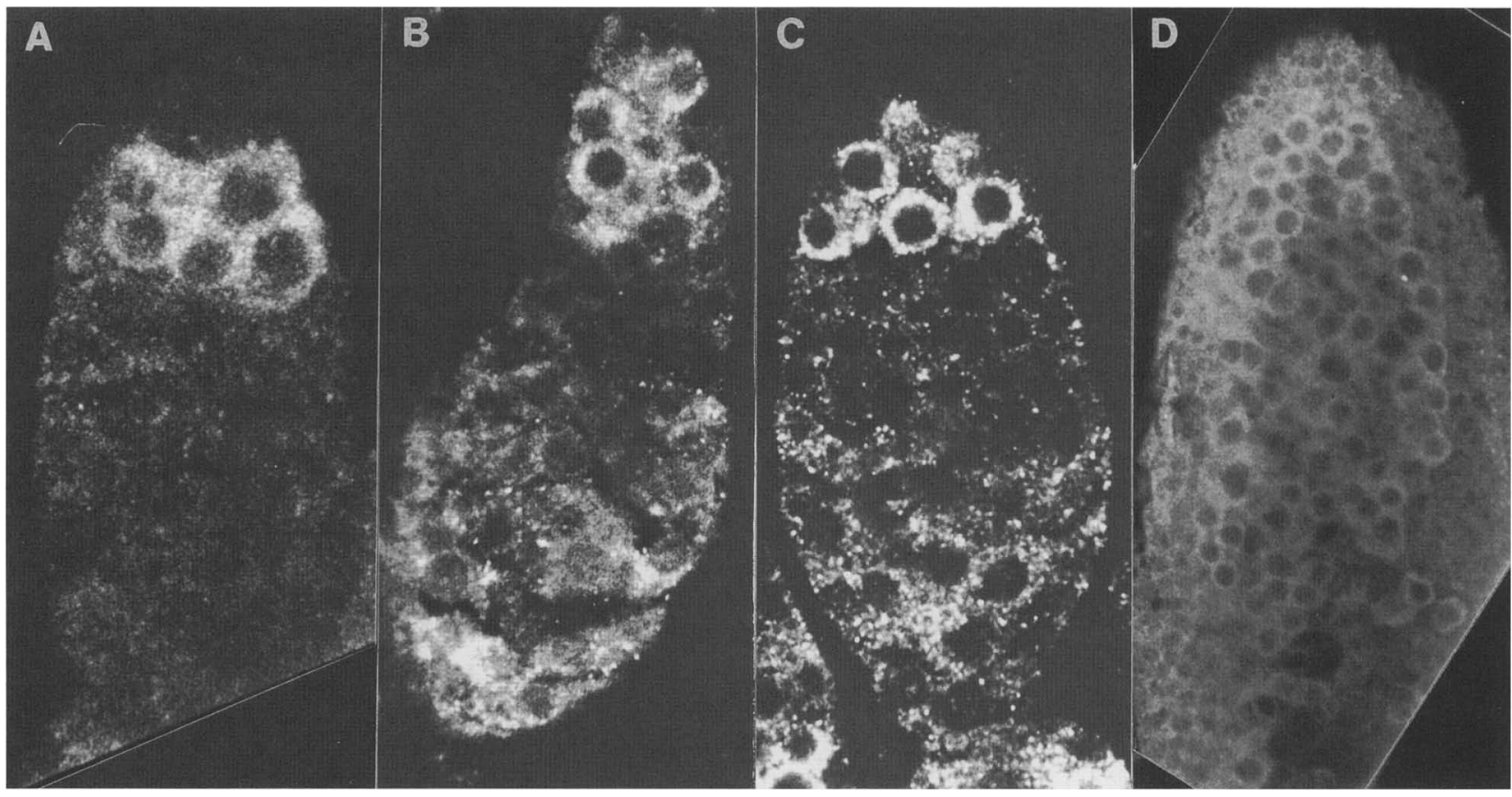

Figure 6. Expression of Sxl protein in orb and bam mutant ovaries. Confocal images of germaria probed with Sxl antibodies. $(A)$ wild-type pattern of Sxl protein expression. Note the high level and cytoplasmic localization in the anterior-most cells. This is followed by a dramatic down-regulation in level and localization of the protein. orb ${ }^{F 343}(B)$ and orb ${ }^{F 303}(C)$ ovaries are shown. Both mutants show the normal cytoplasmic distribution and transition to low levels of protein. $(D)$ bam ovaries, which arrest at an early stage in cyst development, show only the cytoplasmic pattern of Sxl protein expression. The normal decrease in protein level is not observed. 
shown in Figure 7. As controls we also examined ring canals in ovaries from bam, Sx $I^{f 4}$ and the Bic-D mutant, Bic-D $D^{P A 66}$.

Sixteen-cell cysts with interconnecting ring canals can be found in ovaries from both wild type (Fig. 7B) and $B i c-D^{p A 66}$ (Fig. 7F). In both types of cysts, the presumptive oocyte is located at the posterior end of the chamber and is connected to the adjacent nurse cells by four ring canals. However, the Bic-D $D^{P A 66}$ cysts differ from wild type in that the chromosomal DNA of the oocyte undergoes extensive endomitotic replication, and the nucleus in this cell becomes heavily stained by Yo Pro like the other nurse cell nuclei (compare the staining of the wildtype and Bic- $D^{P A 66}$ oocyte nucleus; Fig. 7A,Cl. Although 16-cell cysts also appear to be formed in the orb mutant $\mathrm{orb}^{\mathrm{F3O3}}$, the arrangement of cells in the $F 303$ chambers is abnormal (Fig. $7 \mathrm{H}$ ). The presumptive oocyte is not located at the posterior end of the cyst but instead is usually near the center. As in wild type, it appears to be connected to adjacent cells by four-ring canals, and its chromosomal DNA does not undergo extensive endomitotic replication as judged by the Yo Pro staining pattern (Fig. 7G).

More extreme defects are observed in or $b^{d e c}$ and $o r b^{F 343}$. Although cyst development in these two orb mutants appears to proceed further than it does in either bam or $S x f^{f 4}$ mutant ovaries, the orb mutants do not appear to form 16-cell cysts. In bam and $S x f^{f 4}$ mutant
Figure 7. Assessment of cyst development by ring canals. Ovaries were doubly stained to detect nuclei (with Yo Pro) and ring canals (with rhodamine-conjugated phalloidin) and imaged on a confocal microscope. The same section was imaged for nuclei and ring canals. $(A-H)$ Ovarioles oriented with anterior up. (A) Nuclei in wild-type ovariole. Note the brightly staining nuclei of the polyploid nurse cells. The oocyte nucleus stains poorly and appears as a dark spot. $(B)$ The same section as in $A$, showing ring canals (arrow). The ring canals in the older chambers stain more heavily than those in the early germarial clusters. $(C, F\rangle B i c-D^{P A 66}$ mutant ovaries. $(C)$ Nuclear staining in these egg chambers shows 16 polyploid nurse cells and all nuclei stain heavily. $(F)$ The ring canals of Bic- $D^{P A 66}$ appear to form normally. $(D)$ or $b^{F 343}$ ovary. These ovaries contain apparently normal nuclei (n) at the anterior of the germarium. Toward the posterior many of the nuclei stain weakly suggesting that they are degenerating $(\mathrm{dn}) .(E)$ The same optical section as in $D$ counterstained to show ring canals (arrows). At the posterior where nuclei stain weakly, the ring canals appear to have collapsed into the center of the degenerating cyst. $(G)$ orb $b^{F 303}$ ovary stained for nuclei. The oocyte nucleus (on) is near the center of these egg chambers, whereas nurse cell nuclei (nc) occupy the posterior end. $(H)$ The same section as in $G$ showing ring canals |arrow|. The ring canals in the egg chambers appear normal. (dn) Degenerating nuclei; (n) nuclei; (nc) nurse cell nucleus; (on) oocyte nucleus.

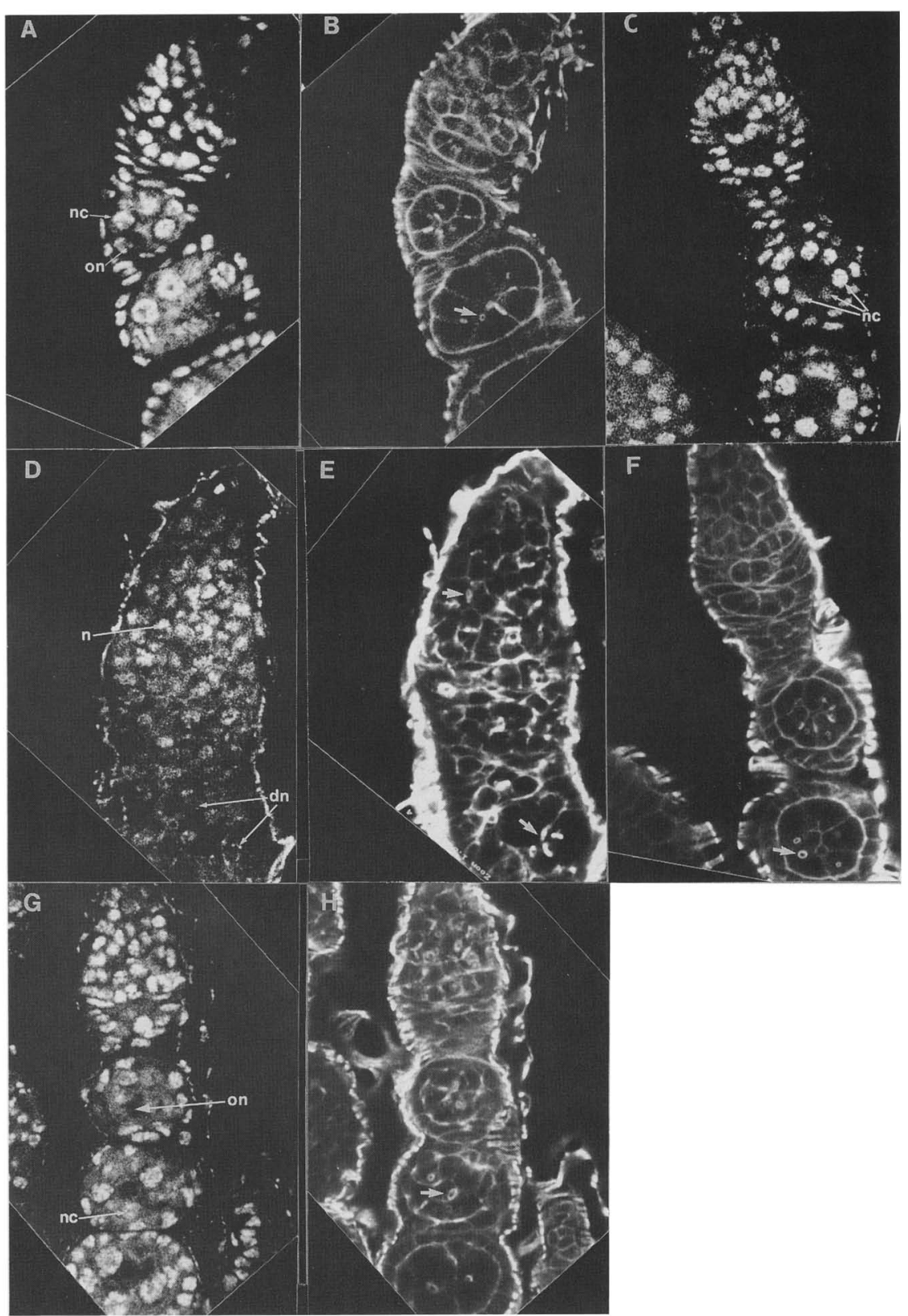


ovaries (data not shown), we observe a few single cells without ring canals and mostly pairs of cells with a single interconnecting ring canal. In contrast, the ring canals found in the older cysts of F343 (Fig. 7E) and dec (not shown) appear larger and stain more heavily with phalloidin. We observe cells with as many as three ring canals in the developing cysts of $F 343$, suggesting that the germ cells have undergone 3 mitotic divisions to give rise to an eight-cell cluster. Some time after the formation of the eight-cell cluster, cyst development in dec and F343 appears to abort, and we do not observe cells with four ring canals. Instead, the membranes separating adjacent cells begin to degenerate and fuse forming large cells with degenerating nuclei (Fig. 7D). Although some of these large cells appear to have four- or even five- or six-ring canals, this is likely the consequence of membrane fusion and the degeneration of adjacent cells, rather than the product of four or more mitotic divisions. The apparent block in cyst development between the 8and 16-cell stage in these two orb mutants coincides well with the time when orb mRNA and protein can first be detected.

Distribution of Bic-D protein in orb mutant ovaries During oogenesis of wild-type ovaries, Bic-D protein expression is first uniformly detected in the stem cells, cystoblasts, and two-cell cysts in region 1 of the germarium (Fig. 8A; see also Suter and Steward 1991). As the two-cell cysts divide to give rise to the four- and eightcell cysts, Bic-D protein can be seen to preferentially segregate in a subset of the cells. This concentration of Bic- $D$ protein in 2.4 cells becomes much more evident in region 2 of the germarium, which contains the 16-cell cysts. As the cysts progress through region 2 , the threedimensional organization of the cells changes, and the small group of cells that accumulates high levels of Bic- $D$ becomes localized to the posterior end of the cyst. By the time the follicle cells begin to envelope the cyst (late region 2) and the early stage 1 egg chamber is formed (region 3), Bic-D protein is highly concentrated in

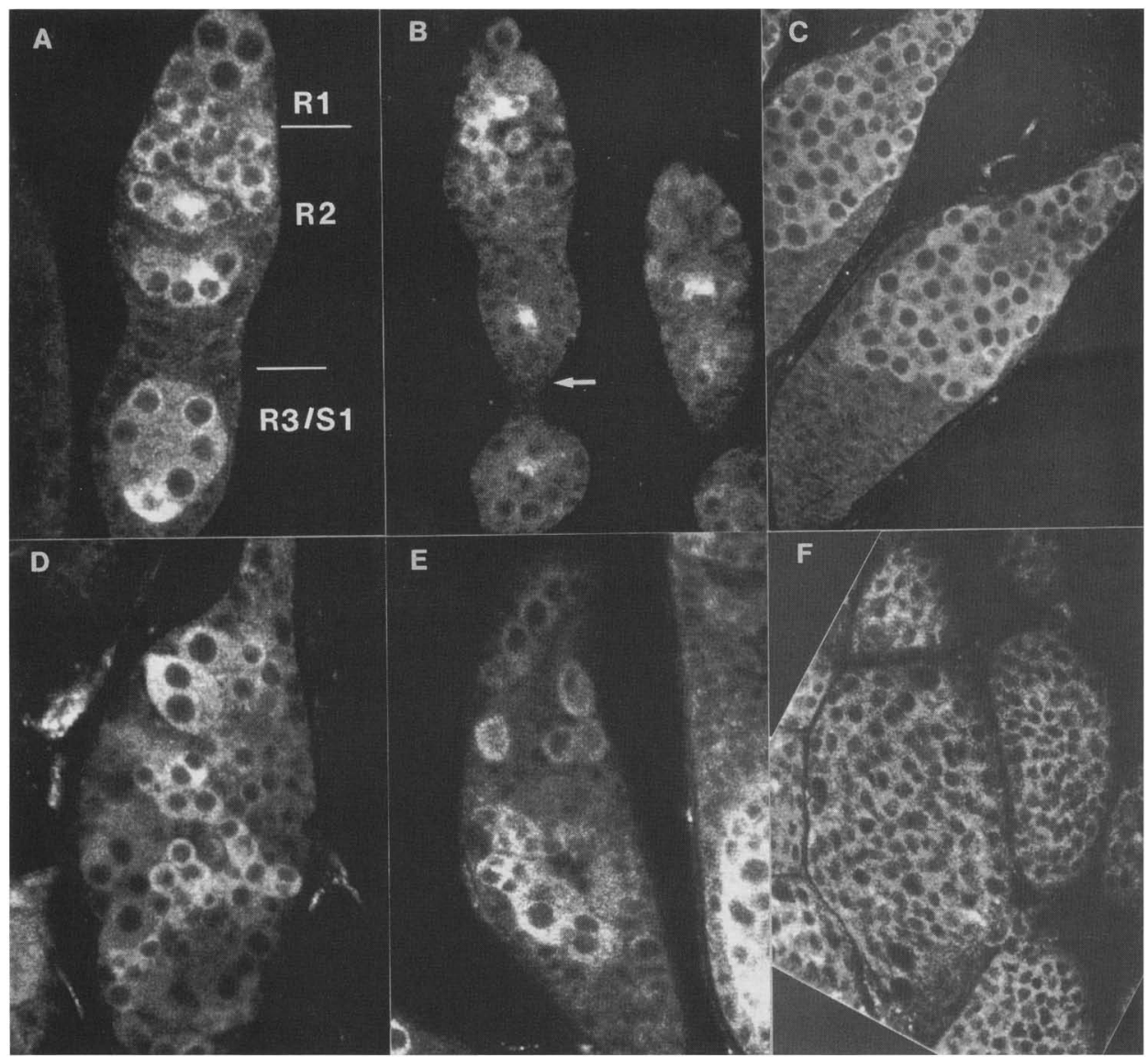

Figure 8. Confocal images showing the distribution of Bic-D protein in orb mutants. $|A|$ Wild-type germarium. Regions 1,2 , and 3 (stage 1 ) of the germarium are indicated. Bic-D protein is localized to the presumptive oocyte in region 2 cysts and in egg chambers. (B) orb ${ }^{F 303}$ ovaries. The end of the germarium is indicated by an arrow. Bic-D protein preferentially accumulates in one cell in very early egg chambers. This cell, however, is not in the posterior of the egg chamber. In older egg chambers Bic-D protein is not as tightly localized to one cell. $(C)$ bam $^{\Delta 86}$ ovaries. The germ-line cells appear to have equal levels of Bic-D protein. $(D)$ or $b^{F 343}$ ovaries. In contrast to bam $^{\Delta 86}$ ovaries, Bic-D protein appears to weakly accumulate in a subset of the cells. $(E)$ orb $b^{\text {dec }}$ ovaries, which appear similar to orb $^{F 343}$ ovaries. $(F) S x l^{f 4}$ ovaries. Like bam ovaries, $S x l$ mutant ovaries show a relatively even distribution of Bic-D protein. 
only one cell at the very posterior end of the cyst, the presumptive oocyte, while the remaining cells in the chamber, the nurse cells, have much lower levels of protein (Fig. 8A; Suter and Steward 1991).

In the or $b^{F 303}$ mutant the initial pattern of Bic-D protein accumulation resembles that in a wild-type germarium; however, abnormalities in Bic-D protein distribution become evident by the time the 16-cell cysts are formed (Fig. 8B). Although Bic-D protein appears to preferentially accumulate in a subset of the cells, this group of cells is not located toward the posterior region of the cyst. Rather, these cells lie near the center of the cyst. The abnormal arrangement of the 16 germ-line cells in the $F 303$ cysts can be seen most clearly when the stage 1 egg chamber is formed (region 3 of the germarium). As in wild type, Bic-D protein is concentrated in only a single cell (the presumptive oocyte) in these early egg chambers; however, this cell is located near the center of the chamber, and not at the posterior end. In addition, the level of accumulation of Bic-D protein in the presumptive oocyte of $F 303$ appears to be higher than in wild-type where the differential between oocyte and nurse cell seems to be less pronounced.

In the orb $b^{d e c}$ and or $b^{F 343}$ mutants, the distribution of Bic-D protein in the early stages of cyst development resembles that observed in wild type. Bic-D protein appears to segregate asymmetrically in a subset of the cells as the mutant cysts progress through the mitotic divisions (see Fig. 8D,E). This pattern of accumulation contrasts with that observed in the tumorous ovaries of bam and $S x l^{f 4}$ females. The ovaries of these mutants are populated by cells (cystoblasts and two-cell cysts in bam and cystoblasts, and two- and four-cell cysts in Sxl) that show a relatively even distribution of Bic-D protein (see Fig. 8C,F). Although the redistribution of Bic-D protein in or $b^{d e c}$ and $o r b^{F 343}$ ovaries during the initial phases of germarial development appears to follow a pattern similar to that observed in wild-type ovaries, at later stages of germarial development and in most older cysts the distribution of Bic-D protein is clearly abnormal. In some mutant cysts high levels of Bic-D protein are found distributed between a large number of cells, whereas in other cysts only low levels of protein are present.

Distribution of orb, Bic-D, K10, and osk RNA in orb mutant ovaries orb, Bic-D (Suter et al. 1989; Wharton and Struhl 1989), K10 (Haenlin et al. 1987; Cheung et al. 1992), osk (Ephrussi and Lehmann 1991; Kim-Ha et al. 1991), and hts (Yue and Spradling 1992) RNAs are targeted to the presumptive oocyte early in oogenesis, and it was of interest to determine whether their localization is affected in the various orb mutants. As might be expected from the early block in cyst development in $o r b^{F 343}$ and $o r b^{d e c}$, localization of these RNAs is severely disrupted in both mutants (data not shown). For example, though low levels of both hts and Bic-D RNA can be detected in or $b^{F 343}$ and $o r b^{\text {dec }}$, neither RNA is localized. osk RNA localization is also abnormal. Although most osk RNA is diffusely distributed in the cysts in these mutants, we occasionally observe some small clusters of cells that have higher levels of the RNA.

The distribution pattern of orb, osk, Bic-D, and K10 RNA in wild-type and or $b^{F 303}$ mutant ovaries is shown in Figure 9. As in wild type, orb RNA appears to preferentially accumulate in a subset of cells in the germarium of F303 mutant ovaries (Fig. 9A,B). As the mutant cysts develop, orb RNA appears to begin localizing to one cell; however, unlike wild-type ovaries, this cell is not at the posterior of the egg chamber but often near the center. In addition, orb RNA does not appear to be as tightly restricted to one cell as it is in wild-type chambers. As the chambers age, orb RNA disappears. Essentially the same pattern of accumulation is observed for osk RNA (see Fig. 9D). In contrast, neither Bic-D (Fig. 9F) nor K10 RNA (Fig. 9H) appears to be localized in orb ${ }^{F 303}$ mutant ovaries.

\section{Discussion}

In the studies reported here, we describe the distribution of Orb protein in wild-type ovaries and the identification and characterization of several mutants in the orb gene. As anticipated from the germ-line-specific pattern of orb expression, these mutants are female sterile. Moreover, our analysis, taken with the studies of Christerson and McKearin (this issue), suggests that orb function is required not at one point but at multiple steps during oogenesis. or $b$ appears to be first required for the formation of 16-cell cysts in the germarium. Once 16-cell cysts are formed, orb seems to be necessary for the organization of the germ cells and their surrounding somatic follicle cells during normal egg chamber development. Finally, the establishment of polarity in the egg and early embryo is dependent on orb function. The maternal effect lethal (mel) allele of orb shows defects in pole cell formation, in anterior-posterior and dorsal-ventral polarity, and in the patterning of the chorion (see accompanying paper by Christerson and McKearin, this issue).

\section{orb is required for the formation of a 16-cell cyst}

In the most severe orb alleles, or $b^{F 343}$ and or $b^{d e c}$, cyst development from the stem cell to the eight-cell cyst stage appears to be normal. This conclusion is suggested by several lines of evidence. First, the bam expression pattern resembles that observed in a wild-type germarium: bam transcripts are detected in cystoblasts and probably also in the two-cell cysts and then disappear in older cysts. In contrast, bam mRNA is not properly down-regulated in the female sterile alleles of $S \times 1$, where germarial development appears to be arrested at the transition between the two- and four-cell cysts. The second comes from an analysis of Sxl protein distribution. In wild-type ovaries, high levels of cytoplasmic Sxl protein are observed in stem cells, cystoblasts, and two-cells cysts, whereas there is an abrupt drop in the level of cytoplasmic Sxl protein in the four- and eight-cell cysts (Bopp et al. 1993). In both orb mutants the distribution of 


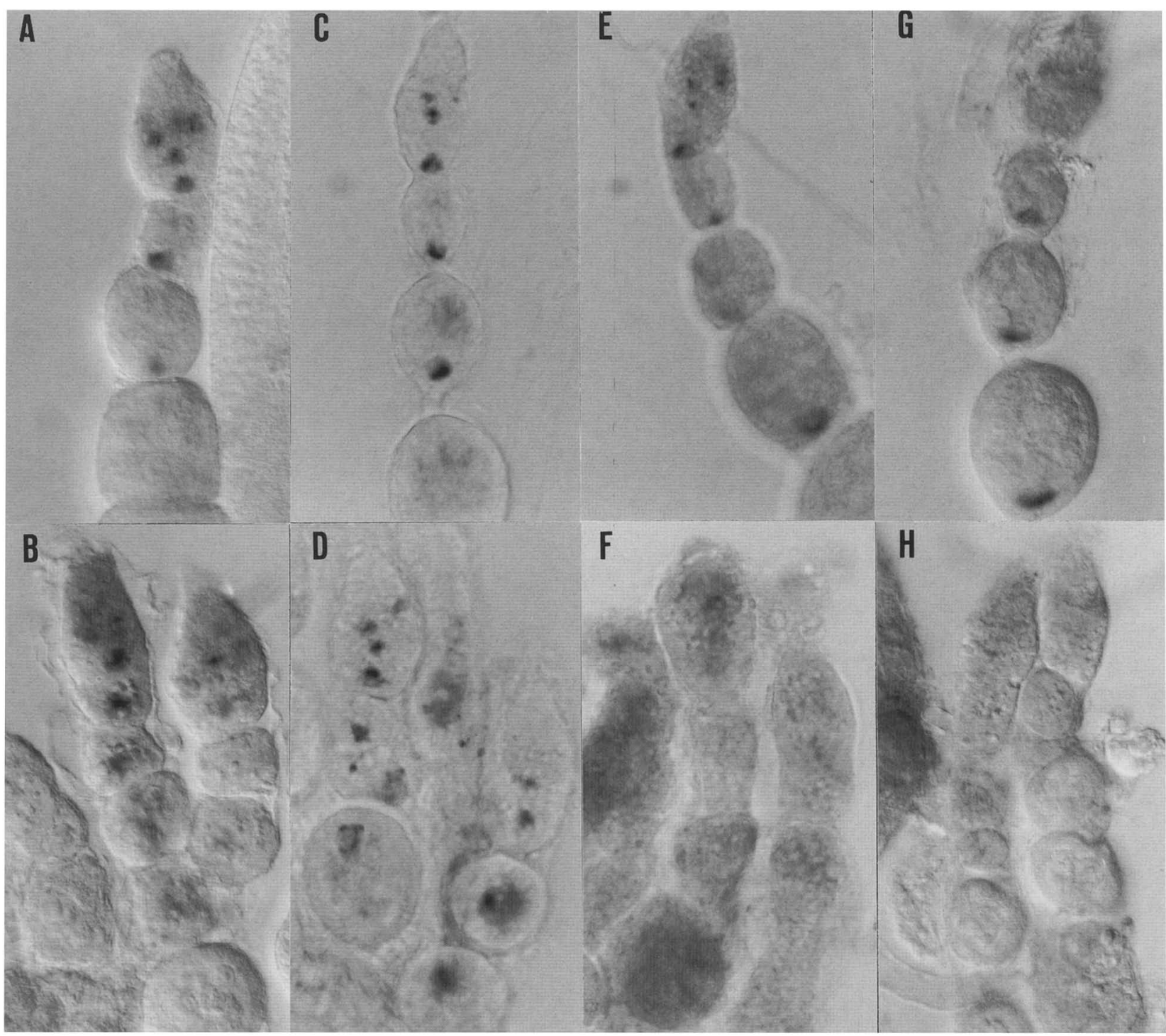

Figure 9. Localization of $o r b$, osk, Bic-D, and $K 10$ RNAs in or $b^{F 303}$ ovaries. Whole-mount preparation of ovaries probed with digoxigenin-labeled orb, osk, Bic-D, or K10. Wild-type and mutant ovaries were hybridized together. $(A, C, E, G)$ Distribution of orb, osk, Bic-D, or K10 RNA, respectively, in wild-type germaria and early egg chambers. $(B, D, F, H)$ Distribution of orb, osk, Bic-D, or K10 RNA, respectively, in rb $^{F 303}$ germaria and early egg chambers. In wild-type ovaries, these RNAs accumulate preferentially in the oocyte during early stages of oogenesis. In $o r b^{F 303}$ ovaries osk and or $b$ RNAs accumulate preferentially in a cell located near the center of the pseudo-egg chambers. K10 and Bic-D RNA, however, are uniformly distributed.

Sxl protein in region 1 of the germarium resembles that seen in wild type. The third line of evidence comes from the analysis of ring canals. In bam mutants, germ cells appear to have only a single ring canal, suggesting that oogenesis is blocked after the first mitotic division at the two-cell cyst stage. In contrast, cells that have as many as 3-ring canals are observed in some of the early orb mutant cysts that have not yet begun to degenerate. The fourth comes from the distribution of Bic-D protein. In both orb mutants Bic-D protein begins to segregate preferentially into a subset of the cells in the developing cyst. In contrast, in bam mutant ovaries, which appear to arrest in oogenesis at the two-cell cyst stage, Bic-D protein remains uniform. This is also true for the female sterile alleles of $S x l$, which appear to arrest somewhat later than bam. These findings would suggest that the orb mutants, dec and F343, are able to execute many of the steps that occur in region 1 of the germarium and that oogenesis may proceed normally at least until the formation of the eight-cell cyst.

In contrast, examination of markers for events that occur in region 2 of the germarium suggests that both mutants do not form a 16-cell cyst. First, cells that have 4-ring canals are not observed in nondegenerating cysts from either mutant. Second, in wild-type ovaries Bic-D protein and osk, hts, and Bic-D mRNAs begin to accumulate in the presumptive oocyte early in region 2 . These molecules do not concentrate in a single cell in 
cysts of either dec or F343. Third, both orb mutants appear to arrest earlier than (the existing) mutations in either $e g l$ or Bic-D. Although $e g l$ and Bic-D mutants have defects in oocyte differentiation, these arise after the formation of a 16-cell cyst. Moreover, the cells found in the egl and Bic-D mutant cysts begin to differentiate as nurse cells, whereas this differentiation does not occur in either or $b^{F 343}$ or or $b^{\text {dec }}$. Fourth, in wild-type as well as in egl and Bic-D mutant ovaries, somatic profollicle cells migrate between and then surround the cysts as they progress from region 1 to region 3 of the germarium. These contacts between profollicle cells and the germline cysts do not appear to be properly initiated in F343 or dec. The profollicle cells do not appear to invaginate in between adjacent germ-line clusters, and cysts surrounded by somatic cells are not observed in either mutant.

Taken together, these results indicate that oogenesis in both $\mathrm{dec}$ and $F 343$ proceeds much like wild type until the 8-cell stage, but is then arrested just prior to or during the formation of the 16-cell cyst. The developmental pathways leading to the formation of nurse cells and an oocyte do not appear to be properly initiated, and cells in the cysts begin to degenerate rather than differentiate. Because our analysis of or $b^{F 343}$ and or $b^{d e c}$ suggests that these two alleles are complete or almost complete lossof-function mutations, it would appear that or $b$ activity may first be required in the female germ line at some point between the third and fourth mitotic divisions. This is close to the time when Orb protein can first be unambiguously detected in a wild-type germarium. How orb might function at this early stage in oogenesis is not entirely clear. orb is predicted to encode a cytoplasmic RNA-binding protein, so presumably this early function involves an interaction between Orb protein and some RNA species. Because the cysts do not progress to the 16-cell state, the RNA in question could encode a protein responsible for controlling the cell cycle, coordinating the last mitotic division (8- to 16-cell cyst) or initiating the transition to meiosis in the presumptive oocyte and its sister cell with four ring canals (King 1970). Alternatively, because the oocyte and nurse cell differentiation pathways do not appear to be initiated, the Orb protein may play a more direct role in cell fate determination in the germ line. Consistent with this idea, when Orb protein is first detected, it is preferentially concentrated in only a subset of the cells in the cyst, with the highest levels ultimately localized in the presumptive oocyte. In this view Orb would function to either localize or regulate the translation of mRNAs encoding products, whose relative concentration in each cell, controls the choice of cell fate.

The role of orb in the differentiation of the nurse cell-oocyte complex

The or $b^{F 303}$ mutant appears to retain some residual or $b$ function and cyst development in this mutant arrests at a later stage than in the apparent null mutations, or $b^{F 343}$ and or $b^{d e c}$. Unlike either or $b^{F 343}$ or or $b^{d e c}, 16$-cell cysts are formed in $F 303$ and the pathways that specify nurse cell and oocyte development are initiated. As observed in wild-type ovaries, somatic profollicle cells begin to surround the mutant cysts as they proceed through the germarium, and pesudo-egg chambers are pinched off at the end of the germarium. Additionally, the cells in these pseudo-egg chambers begin to differentiate into nurse cells and an oocyte. The nurse cells in these chambers form polyploid nuclei characteristic of nurse cells, while the presumptive oocyte begins to accumulate several oocyte-specific mRNAs (orb RNA, osk RNA, and hts RNA) and protein (Bic-D). Although these chambers initiate the differentiation pathways for nurse cells and oocyte, they do not properly execute these pathways. Other oocyte markers, Bic-D and K10 RNAs do not accumulate in the $F 303$ presumptive oocyte, and the threedimensional organization of the mutant chambers is abnormal. In wild-type ovaries, the presumptive oocyte (and its sister cell with 4-ring canals) is located near the center of the 16-cell cyst when it is first formed at the beginning of region 2 of the germarium. As the cyst progresses through region 2 , the cells reorganize and the oocyte moves toward the posterior end of the cyst. By the time the cyst reaches the base of the germarium in region 3 , the oocyte has been repositioned to the posterior end of the egg chamber where it remains throughout the rest of oogenesis. In $\mathrm{orb}^{\mathrm{F} 303}$ ovaries the reorganization of the nurse cell-oocyte complex does not occur, and the presumptive oocyte remains near the center of the $F 303$ chambers even after they have pinched off from the germarium. By comparison, in Bic-D mutant ovaries the presumptive oocyte relocalizes properly to the posterior end of the cyst, even though it subsequently aborts the oocyte pathway and instead begins to differentiate as a nurse cell (Suter and Steward 1991). In addition to these defects in oocyte differentiation and the organization of the germ cells, contacts between germ line and soma are not properly established in $F 303$, and in many cases the egg chambers are not completely surrounded by follicle cells.

The phenotypic defects in F303 correlate with the failure to modify and localize the Orb protein. Western analysis of Orb protein indicates that only one of the two isoforms, the faster migrating species, is present in $F 303$ ovaries. It seems likely that the slower isoform is absent not because of the block in oogenesis in $F 303$ but, rather, because the F303 lesion somehow prevents the Orb protein from being properly modified. This view is supported by the observation that both isoforms are present in ovaries from bam and $\mathrm{Sx}^{14}$ mutants, which appear to arrest at an earlier point in oogenesis than F303. In addition to the apparent defects in modification, Orb protein is not properly localized in F303 cysts. Although the protein begins to accumulate in a cell or small group of cells during the early development of the cyst, the accumulation is not very high and most of the cells in the cyst appear to have nearly equivalent levels of protein. It is conceivable that the modification(s) of the Orb protein that generate the slower migrating species might be required for high levels of protein to accumulate in the 
presumptive oocyte. In addition, it is not clear that the cell(s) accumulating higher levels of Orb protein even corresponds to the presumptive oocyte. Other oocyte markers such as Bic-D protein and osk RNA appear to accumulate in the single nonpolytenized cell located near the center of the cyst. In contrast, the cell (or cells) having the higher concentration of Orb protein is not always in the center but, instead, can be located at the side or at the anterior or posterior edge of the cyst.

Taken together, these results suggest that the block in oogenesis in F303 stems from a failure of the Orb protein to properly localize one or more RNAs to the presumptive oocyte. Consistent with this postulated defect in mRNA targeting, we find Bic-D mRNA is mislocalized in F303. However, this failure to localize Bic-D RNA is unlikely to be responsible for all of the defects observed in $F 303$ because the known Bic-D mutants have considerably less severe phenotype (see above and Suter and Steward 1991). Rather, the aberrant development of the egg chamber would result from the failure to localize other RNAs that encode proteins that play a critical role in mediating the three-dimensional reorganization of the nurse cell-oocyte complex, and/or the further differentiation of the oocyte. Such proteins could, for example, be components of the cytoskeleton that initiate the reorganization process or could be membrane-bound receptors involved in communication or adhesion between the oocyte and the posterior somatic profollicle cells (Ruohola et al. 1991; Schupbach et al. 1991; Peifer et al. 1993).

\section{Possible functions of the Orb protein}

Genetic analysis indicates that orb function is required at multiple steps in oogenesis: for the formation of a 16-cell cyst, the differentiation of the egg chamber, and the establishment of polarity. Many of the genes affecting these processes encode localized RNAs whose distribution coincides with that of Orb protein, suggesting that orb may function in the localization of these RNAs. orb mutations result in the mislocalization of Bic-D, $\mathrm{K} 10$, osk, and grk mRNAs. orb could participate in RNA localization at several different levels. The first may be in the transport of specific RNA species from the nurse cells into the oocyte, a possibility supported by the gradient of Orb protein both in the germarium and in later egg chambers. The highest levels of Orb protein are found in the oocyte, the nurse cells closest to the oocyte have intermediate levels, whereas those farthest from the oocyte have the lowest levels of protein. A second function of Orb protein would be to anchor specific RNAs in the oocyte, presumably to some component of the cytoskeleton assembled at the egg cortex. This possibility is suggested by the predominantly cortical localization of Orb protein (which is particularly evident between stages 5 and 10|. Because Orb protein appears to preferentially accumulate at the very posterior end of the oocyte during the previtellogenic stages of oocyte development, it might anchor mRNA species involved in the determination of pole cells and/or posterior segments to the posterior cortex of the oocyte such as osk (Christerson and McKearin, this issue). After the onset of vitellogenesis, Orb protein accumulates at high levels along the dorsal-ventral axis close to the oocyte-nurse cell border. The Orb protein deposited during this stage may function in the anchoring of one or more of the mRNA species involved in determining the dorsal-ventral polarity of the egg shell and embryo. Likely candidate mRNAs would be encoded by the grk and $K 10$ genes. Although we have argued here that Orb may play a key role in localizing RNAs to distinct regions of the oocyte, the distribution of Orb protein along the entire cortex of the egg, particularly at later stages of oogenesis, would require that it act in conjunction with other, more specifically targeted proteins. In this view, other RNA-binding proteins such as Stau /which is required for the posterior localization of osk mRNA; Ephrussi et al. 1991; St. Johnson et al. 1991; Gatignol et al. 1993/ would target specific RNAs to distinct regions of the oocyte where Orb would assist in anchoring these RNAs. In addition, the broad distribution of Orb protein suggests that it may have a more general role in anchoring maternal mRNAs to the egg cortex. Finally, Orb protein might be involved in regulating the translation of bound RNAs. It could function to repress translation of these RNAs until after fertilization as is observed for many different maternal mRNAs. Alternatively, Orb protein could facilitate the translation of the RNAs once they have been localized to the appropriate site within the oocyte.

\section{Materials and methods}

Fly stocks

The wild-type strain Oregon $\mathrm{R}$ is described in Lindsley and Grell (1968). The Bic-D $D^{P A 66}$ and Bic-D $D^{R 26}$ recessive female sterile alleles and $D f(2 L) T W 119$ were described in Steward et al. (1987), Suter et al. (1989), and Schüpbach and Wieschaus (1991). The egI ${ }^{\text {WU5O }}$ and $e g l^{R C 12}$ alleles and $D f(2 R) b w-S 46$ are described in Schüpbach and Wieschaus (1991). bam 86 (McKearin and Spradling 1990) and orb $b^{d e c}$ were obtained from D. McKearin. Sx ${ }^{f 4}$ has been described previously (Bopp et al. 1993). or $b^{F 303}$ and $o r b^{F 343}$ are members of a collection of female sterile mutations on the third chromosome (C. Nüsslein-Volhard, unpubl.). Df(3R)MSu244 is described in Reuter et al. (1986) and Wustmann et al. (1989).

\section{Generation of monoclonal antibodies}

The BanI-BamHI fragment from the D5 ovarian/embryonic cDNA (which contains 671 of the 915 amino acids of the ovarian protein including the putative RNA-binding domains) was subcloned into the BamHI site of the pET-3c (pAR) expression vector (Studier and Moffat 1986). Upon induction, the chimeric protein produced is a fusion of the partial orb polypeptide downstream of the first 11 amino acids of the viral T7 gene $\phi 10$. The $\phi 10-$ Orb fusion protein was prepared by SDS gel purification from induced cultures of Escherichia coli BL21(DE3) carrying the pET-3c/orb plasmid. Generation of monoclonal antibody lines was performed according to Bopp et al. (1991). Parental hybridoma lines were screened with the same partially purified $\phi 10-$ orb fusion protein used for injection. The resultant positives were confirmed by immunoblots of induced extracts of 
bacteria containing the pET-3c vector or $\mathrm{pET}-3 \mathrm{c} / \mathrm{orb}$. Several parental hybridoma lines were subcloned by limiting dilution.

\section{Western analysis}

Ovary, testis, and embryo extracts were prepared according to Suter et al. (1991). To resolve the isoforms, samples were loaded on $10 \%$ SDS-polyacylamide gels $130 \%$ acrylamide $/ 0.2 \%$ bisacrylamide stock). After electrophoresis, the protein was transferred to nitrocellulose paper in Tris-glycine buffer for $2 \mathrm{hr}$ at $250 \mathrm{~mA}$. To determine whether similar amounts of protein were loaded in each lane, the blots were stained with Ponceau S red. After blocking in 5\% low-fat dry milk powder (NFDM) in TBST (TBS/0.05\% Tween 20; Sigma), the blot was incubated overnight at $4^{\circ} \mathrm{C}$ with first antibody (hybridoma supernatants) at a 1:20 dilution in TBST with NFDM. The antigen antibody complex was detected by use of the enhanced chemiluminescence (ECL) system from Amersham. The blot was incubated for $2 \mathrm{hr}$ with an anti-mouse biotinylated antibody/Vector Laboratories, Inc.), subsequently for 1-2 hr with horseradish peroxidase (HRP)-streptaviden complex, and finally ECL reagents were incubated with the blot for detection.

Prestained protein molecular mass standards (Bethesda Research Laboratory, Inc.) $(208,100.6,71.2$, and $43.5 \mathrm{kD})$ and high molecular mass standards (Bio-Rad, Inc.) $(200,116.2,97.4$, and 66.2) were used as size markers.

Blots were stripped for reprobing with anti-Drosophila nuclear lamin rabbit polyclonal antibody (Gruenbaum et al. 1988). The blot was incubated in $2 \mathrm{M}$ glycine $(\mathrm{pH} 2.8)$ for $10 \mathrm{~min}$. After extensive washing with TBST, the blot was incubated overnight at $4^{\circ} \mathrm{C}$ with anti-lamin rabbit polyclonal antibody at a $1: 2000$ dilution in TBST with NFDM. The antigen antibody complex was detected by use of the ECL system from Amersham. The blot was incubated for $2 \mathrm{hr}$ with an anti-rabbit biotinylated antibody (Vector Laboratories, Inc.), subsequently for $1-2 \mathrm{hr}$ with HRP-streptavidin complex, and finally ECL reagents were incubated with the blot for detection.

\section{In situ hybridization to ovaries}

Whole-mount in situ hybridizations were performed according to Tautz and Pfeifle (1989) as described previously (Lantz et al. 1992).

\section{Immunocytochemistry}

Ovaries were fixed in $4 \%$ paraformaldehyde $/ 1 \times$ PBS and blocked with $1 \%$ BSA in PBST $(1 \times$ PBS $/ 0.1 \%$ Triton-X $100 /$ $0.05 \%$ Tween 80 ) for $3-5 \mathrm{hr}$. After overnight incubation at $4^{\circ} \mathrm{C}$ and $1 \mathrm{hr}$ at room temperature with monoclonal supernatants in $0.1 \%$ BSA in PBST $11: 30$ dilution of the $6 \mathrm{H} 4$ or $4 \mathrm{H} 8$ orb antibody; 1:50 dilution of five Bic-D antibodies: 1B11, 2E11, $2 \mathrm{G} 10 ; 1,3 \mathrm{D} 7 ; 1,4 \mathrm{C} 2$ ), the samples were incubated for $2 \mathrm{hr}$ with an anti-mouse biotinylated antibody and subsequently with FITC-streptavidin. The tissue was mounted in $75 \%$ glycerol/ PBS with $1 \mu \mathrm{g} / \mathrm{ml}$ of propidium iodide. When only protein was stained, Cy-3 conjugated streptavidin was used. Homozygous orb mutant ovaries were used for all analysis. For analysis of Orb protein distribution in Bic-D and egl ovaries, hemizygous mutant ovaries were used (Bic-D/Df(2L)TW119 and $e g I / D f(2 R)$ $b w$-S46). Staining with $S x l$ antibodies was done as described previously (Bopp et al. 1993). Imaging was done by laser scanning confocal microscopy (Krypton-Argon Laser, Bio-Rad MRC $600)$.

\section{Rhodamine-phalloidin staining}

Wild-type and mutant ovaries were dissected in PBS, placed on ice, and fixed for $10 \mathrm{~min}$ in $8 \%$ formaldehyde. After several washes in PBST, the ovaries were incubated for $25 \mathrm{~min}$ with rhodamine-phalloidin (Molecular Probes) at a concentration of $15 \mu \mathrm{g} / \mathrm{ml}$. The ovaries were washed for $\sim 1 \mathrm{hr}$ with five to six changes of PBS and then incubated in $1 \mu \mathrm{M}$ Yo Pro (Molecular Probes) for $10 \mathrm{~min}$ at room temperature. After two washes in PBS, the ovaries were mounted in Aqua-poly/mount (Polysciences, Inc.) and examined with a confocal imaging system.

\section{Acknowledgments}

We thank D. McKearin and L. Christerson for sharing their results prior to publication and for fly stocks. Our thanks go to J. Goodhouse for instruction and guidance in using the confocal microscope, N. Ly for her assistance in screening for orb mutants, and M. Marlow for help in raising monoclonal antibodies to Orb protein. We particularly thank C. Nüsslein-Volhard for the kind gift of third chromosome female sterile mutants. Our special thanks to B. Suter and R. Steward for Bic-D DNA and antibodies. We also thank members of the Schedl and Steward laboratories for stimulating discussions and are grateful to K. Miller and R. Clifford for helpful suggestions on the manuscript.

The publication costs of this article were defrayed in part by payment of page charges. This article must therefore be hereby marked "advertisement" in accordance with 18 USC section 1734 solely to indicate this fact.

\section{References}

Bopp, D., J.I. Horabin, R.A. Lersch, T.W. Cline, and P. Schedl. 1993. Expression of the Sex-lethal gene is controlled at multiple levels during Drosophila oogenesis. Development 118: 797-812.

Cheung, H.-K., T. Serano, and R.S.Cohen. 1992. Evidence for a highly selective RNA transport system and its role in establishing the dorsoventral axis of the Drosophila. Development 114: 653-661.

Christerson, L. and D. McKearin. 1994. orb is required for anteroposterior and dorsoventral patterning during Drosophila oogenesis. Genes \& Dev. (this issue).

Driever, W. and C. Nüsslein-Volhard. 1988a. A gradient of bicoid protein in Drosophila embryos. Cell 54: 83-93.

- 1988b. The bicoid protein determines position in the Drosophila embryo in a concentration-dependent manner. Cell 54: 95-104.

Ephrussi, A., L.K. Dickenson, and R. Lehmann. 1991. oskar organizes the germ plasm and directs localization of the posterior determinant nanos. Cell 66: 37-50.

Frohnhöfer, H.G. and C. Nüsslein-Volhard. 1987. Maternal genes required for the anterior localization of bicoid activity in the embryo of Drosophila. Genes \& Dev. 1: 880-890.

Gatignol, A., C. Buckler, and K.T. Jeang. 1993. Relatedness of an RNA-binding motif in human immunodeficiency virus type 1 TAR RNA-binding protein TRBP to human P1/ds1 kinase and Drosophila Staufen. Mol. Cell. Biol. 13: 2193-2202.

Govind, S. and R. Steward. 1991. Dorsoventral polarity in the Drosophila embryo: Signal transduction and nuclear targeting. Trends Genet. 7: 119-125.

Gruenbaum, Y., Y. Landesman, B. Drees, J.W. Bare, H. Saumw- 
ber, M. Paddy, J.W. Sedat, D.E. Smith, B.M. Brenton, and P.A. Fisher. 1988. Drosophila nuclear lamin precursor $\mathrm{Dm}_{\mathrm{o}}$ is translated from either of two developmentally regulated mRNA species apparently encoded by a single gene. I. Cell Biol. 106: 585-596.

Haenlin, M., C. Roos, A. Cassab, and E. Mohier. 1987. Oocytespecific transcription of $f_{s}(1)$ K10: A Drosophila gene affecting dorsal-ventral developmental polarity. EMBO J. 6: 801807.

Kalthoff, K. 1973. Action spectra for UV induction and photoreversal of a switch in the developmental program of an insect (Smittia). Photochem. Photobiol. 18: 355-364.

1979. Analysis of a morphogenetic determinant in an insect embryo (Smittia sp; Chironmidae, Diptera). In Determinants of spatial organization (ed. S. Subtelny and I. Konigsberg), pp. 79-126. Academic Press, New York.

Kandler-Singer, I. and K. Kalthoff. 1976. RNase sensitivity of an anterior morphogenetic determinant in an insect egg (Smittia sp; Chironmidae, Diptera). Proc. Natl. Acad. Sci. 73: 3739-3743.

Kim-Ha, I., J.L. Smith, and P.M. Macdonald. 1991. oskar mRNA is localized to the posterior pole of the Drosophila embryo. Cell 66: 23-35.

King, R.C. 1970. Ovarian development in Drosophila melanogaster. Academic Press, New York.

Lantz, V., L. Ambrosio, and P. Schedl. 1992. The Drosophila orb gene is predicted to encode sex-specific germline RNA-binding proteins and has localized transcripts in ovaries and early embryos. Development 115: 75-88.

Lehmann, R. 1992. Germ-plasm formation and germ-cell determination in Drosophila. Curr. Opin. Genet. Dev. 2: 543549.

Lindsley, D. and R. Grell. 1968. Genetic variations of Drosophila melanogaster. Carnegie Inst. Wash. Publ. 627.

MacDonald, P.M. 1992. The means to the ends: Localization of maternal messenger RNAs. Sem. Dev. Biol. 3: 413-424.

MacDonald, P.M., S.K.-S. Luk, and M. Kilpatrick. 1991. Protein encoded by the exuperantia gene is concentrated at sites of bicoid mRNA accumulation in Drosophila nurse cells but not in oocytes or embryos. Genes \& Dev. 5: 2455-2466.

Mahowald, A.P. and M.P. Kambysellis. 1980. Oogenesis. In The genetics and biology of Drosophila, (ed. M. Ashburner and T.R.F. Wright), Vol. 2, pp. 141-224, Academic Press, New York.

Marcey, D., W.S. Watkins, and T. Hazelrigg. 1991. The temporal and spatial distribution of maternal exuperantia protein: Evidence for a role in establishment but not maintenance of bicoid mRNA localization. EMBO J. 10: 4259-4266.

McKearin, D.M. and A.C. Spradling. 1990. Bag-of-marbles: A Drosophila gene required to initiate both male and female gametogenesis. Genes \& Dev. 4: 2242-2251.

Melton, D.A. 1987. Translocation of a localized maternal mRNA to the vegetal pole of Xenopus oocytes. Nature 328: 80-82.

Neuman-Silberberg, F.S. and T. Schupbach. 1993. The Drosophila dorsoventral patterning gene gurken produces a dorsally localized RNA and encodes a TGF $\alpha$-like protein. Cell (in press).

Peifer, M., S. Orsulic, D. Sweeton, and E. Wieschaus. 1993. A role for the Drosophila segment polarity gene armadillo in cell adhesion and cytoskeletal integrity during oogenesis. Development 118: 1191-1207.

Pokrywka, N.-J. and E. Stephenson. 1991. Microtubules mediate the localization of bicoid RNA during Drosophila oogenesis. Development 113: 55-66.

Reuter, G., R. Dorn, G. Wustmann, B. Friede, and G. Rauh.
1986. Third chromosome suppressor of position-effect variegation loci in Drosophila melanogaster. Mol. Gen. Genet. 202: $481-487$.

Ruohola, H., K.A. Bremer, D. Baker, J.R. Swedlow, L.Y. Jan, and Y.N. Jan. 1991. Role of neurogenic genes in establishment of follicle cell fate and oocyte polarity during oogenesis in Drosophila. Cell 66: 433-449.

St. Johnston, D. and C. Nüsslein-Volhard. 1992. The origin of pattern and polarity in the Drosophila embryo. Cell 68: 201-219.

St Johnston, D., W. Driever, T. Berleth, S. Richstein, and C. Nüsslein-Volhard. 1989. Multiple steps in localization of $b i$ coid RNA to the anterior pole of the Drosophila oocyte. Development. (Suppl.) 107: 13-19.

St. Johnston, D., D. Beuchle, and C. Nüsslein-Volhard. 1991. staufen, a gene required to localize maternal RNAs in the Drosophila egg. Cell 66: 51-63.

Schüpbach, T. and E.F. Wieschaus. 1991. Female sterile mutations on the second chromosome of Drosophila melanogaster: II. Mutations blocking oogenesis or altering egg morphology. Genetics 129: 1119-1136.

Schupbach, T., R.J. Clifford, L.J. Manseau, and J.V. Price. 1991. Dorsoventral signaling processses in Drosophila oogenesis. In Cell-cell interactions in early development (ed. J. Gerhart), pp. 163-174. Wiley and Sons, New York.

Steward, R., L. Ambrosio, and T. Schüpbach. 1987. Polarity in the oocyte and embryo of Drosophila. UCLA Symp. Mol. Cell. Bio. New Ser. 51: 39-50.

Steward, R., S.B. Zusman, L.H. Juang, and P. Schedl. 1988. The Dorsal protein is distributed in a gradient in the early Drosophila embryos. Cell 55: 487-495.

Studier, F.W. and B.A. Moffat. 1986. Use of bacteriophage T7 polymerase to direct high-level expression of cloned genes. $I$. Mol. Biol. 189: 113-130.

Suter, B. and R. Steward. 1991. The role of the Bicaudal-D protein and its phosphorylation in Drosophila oocyte differentiation. Cell 67: 917-926.

Suter, B., L. Romberg, and R. Steward. 1989. Bicaudal-D, a Drosophila gene involved in developmental asymmetry: Localized transcript accumulation in ovaries and sequence similarity to myosin heavy chain tail domains. Genes \& Dev. 3: 1957-1968.

Tautz, D. and C. Pfeifle. 1989. A nonradioactive in situ hybridization method for the localization of specific RNAs in Drosophila embryos reveals a translational control of the segmentation gene hunchback. Chromosoma 98: 81-85.

Theurkauf, W.E., S. Smiley, M.L. Wong, and B.M. Alberts. 1992. Reorganization of the cytoskeleton during Drosophila oogenesis: Implications for axis specification and intracellular transport. Development 115: 923-936.

Thomsen, G.H. and D.A. Melton. 1993. Processed Vgl protein is an axial mesoderm inducer in Xenopus. Cell 74: 433-441.

Weeks, D.L. and D.A. Melton. 1987. A maternal mRNA localized to the vegetal hemisphere in Xenopus eggs codes for a growth factor related to TGF- $\beta$. Cell 51: 861-867.

Wharton, R.P. and G. Struhl. 1989. Structure of the Drosophila Bicaudal $D$ protein and its role in localizing the posterior determinant nanos. Cell 59: 881-892.

Wustmann, G., J. Szidonya, H. Taubert, G. Reuter. 1989. The genetics of position-effect variegation modifying loci in Drosophila melanogaster. Mol. Gen. Genet. 217: 520-527.

Yisraeli, J.K. and D.A. Melton. 1988. The maternal mRNA Vg1 is correctly localized following injection into Xenopus oocytes. Nature 336: 592-595.

Yue, L. and A. Spradling. 1992. hu-li tai shao, a gene required for ring canal formation during Drosophila oogenesis, encodes a homolog of adducin. Genes \& Dev. 6: 2443-2454. 


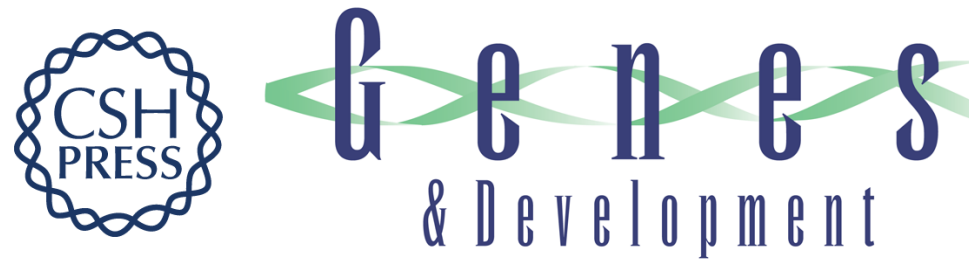

\section{The Drosophila orb RNA-binding protein is required for the formation of the egg chamber and establishment of polarity.}

V Lantz, J S Chang, J I Horabin, et al.

Genes Dev. 1994, 8:

Access the most recent version at doi:10.1101/gad.8.5.598

References This article cites 41 articles, 16 of which can be accessed free at:

http://genesdev.cshlp.org/content/8/5/598.full.html\#ref-list-1

License

Email Alerting

Service

Receive free email alerts when new articles cite this article - sign up in the box at the top right corner of the article or click here.

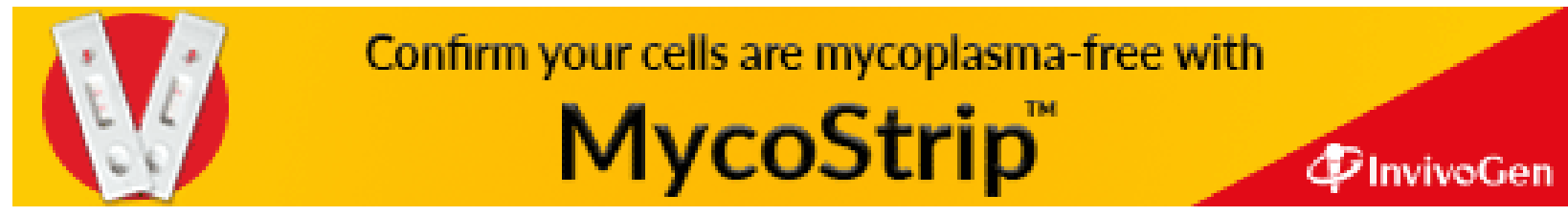

